\title{
Cryotherapy in the management of paroxysmal trigeminal neuralgia
}

\author{
JOANNA M ZAKRZEWSKA \\ From the Department of Oral Medicine, University of London, Institute of Dental Surgery, London, UK
}

SUMMARY Cryotherapy for the relief of pain is widely used in many conditions. The results of 83 cryotherapy sessions in 29 patients with paroxysmal trigeminal neuralgia are reviewed over a five year period. Sixty three per cent of treated nerves, $41 \%$ of patients were pain free over one year and there was no permanent sensory loss.

Despite recent advances in treatment, trigeminal neuralgia remains an incapacitating condition which is difficult to treat successfully in every patient. At present it is standard practice to use carbamazepine as the first line of treatment, sometimes with the later addition of phenytoin. Even though many patients can be managed in the long term by carbamazepine, side effects are often unpleasant and quite a number of patients become intolerant. Taylor et $\mathrm{al}^{1}$ reported a 16 year follow up on 143 patients treated with carbamazepine and found it to be effective in 99 patients $(69 \%)$, but 19 of those patients later became resistant to the drug and required a variety of surgical procedures.

In order to avoid major surgery, numerous peripheral techniques have been used. These have included peripheral neurectomy, ${ }^{2}$ alcohol, ${ }^{34}$ or phenol injections, peripheral radiofrequency thermolysis, ${ }^{5}$ removal of jaw cysts, ${ }^{6}$ and peripheral streptomycin and lidocaine injections. ${ }^{7}$ None of the techniques appears to be curative and some may cause complications such as neuromas, anaesthesia dolorosa and neurological deficits.

The use of cryotherapy (cryoanalgesia) was first reported by Lloyd et $a l^{8}$ in 1976 with encouraging results. They treated 64 patients suffering from intractable pain, six of whom had "facial pain". Cryotherapy was used in a variety of facial pains, including post herpetic neuralgia, atypical facial pain and par-

Address for reprint requests: Dr JM Zakrzewska, Eastman Dental Hospital, 256 Gray's Inn Road, London WC1X 8LD, UK.

Received 30 April 1986 and in revised form 21 July 1986. Accepted 26 July 1986 oxysmal trigeminal neuralgia. They found that only the last named group really benefited from cryotherapy. Barnard et al ${ }^{9}$ in 1981 reported the use of cryotherapy in 24 patients with paroxysmal trigeminal neuralgia. Patients had a median relief period of 186 days but at the end of one year only $16 \%$ had full pain relief. Since 1978, cryotherapy for the relief of paroxysmal trigeminal neuralgia has been used at the Eastman Dental Hospital. ${ }^{10-12}$ Initially nitrous oxide was used as a refrigerant and then liquid nitrogen came to be used as the standard procedure. Since then 145 patients have been treated and 247 open nerve freezes performed on these patients.

\section{Material and methods}

Thirty nine patients were first treated with cryotherapy using liquid nitrogen over five years ago. Of these, six were lost to follow up, two died and two later underwent radiofrequency thermocoagulation of the Gasserian ganglion. Therefore 29 patients were considered who had been followed up for at least five years. The group included 16 females and 13 males with a mean age of 54 years (range 18-76 years). Twenty one of the patients had pain on the right side; 10 of these involved the right infra-orbital nerve. None in this series had pain in the ophthalmic division. Forty five per cent of the patients had suffered from paroxysmal trigeminal neuralgia for a period between 1 to 5 years. Strict diagnostic criteria were used. Pain was in the distribution of the trigeminal nerve and was of an electric shock, shooting or stabbing character. It was of short duration and showed periods of complete remission. Trigger zones could be elicited by innocuous stimuli such as light touch and vibration. No frank sensory deficit was found on gross neurological testing and radiological investigations, that is, lateral and posterio-anterior skull radiographs and orthopantomograms of the jaws were nor- 


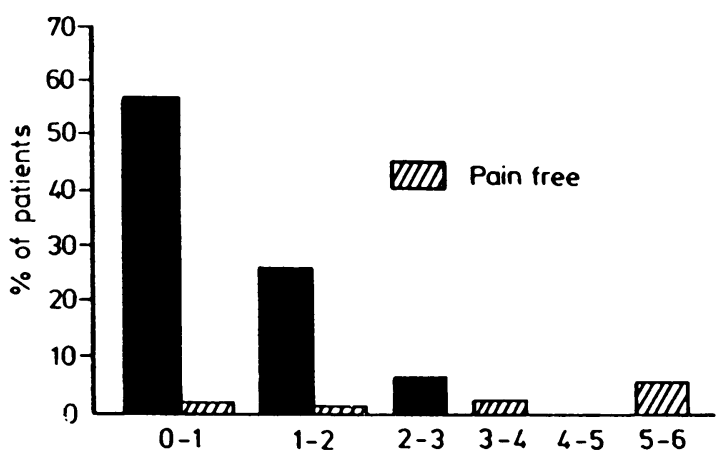

Fig Total pain control periods. 83 cryotherapy sessions.

mal. The injection of local anaesthesia into the trigger zones abolished the pain. All patients had been treated with carbamazepine and although initially they showed a response, they subsequently became intolerant or unresponsive to it. Over $50 \%$ of the patients had suffered from the disease from 1 to 5 years. None had undergone neurosurgical procedures or had any neurolytic injections. Those with atypical clinical features were excluded, including those who had secondary trigeminal neuralgia. Repeat cryotherapy was done on those patients in whom pain returned.

\section{Cryotherapy technique}

Identification of the affected branch or branches was achieved prior to cryotherapy by injection of local anaesthesia with consequent abolition of pain. Patients were treated under intravenous sedation, together with local anaesthesia. The affected nerves were exposed using intra-oral techniques as far as possible. The exposed nerve was then frozen with the DFS 30 system (Spembly, Guildford), with a thermostatically controlled temperature of $-120^{\circ} \mathrm{C}$. The cycle of a 2 minute freeze, followed by a 5 minute thaw was performed three times, taking care not to crush the nerve. If two branches were affected, both were treated simultaneously; most commonly these were the long buccal and mental nerves.

\section{Results}

Between them, the 29 patients had undergone 83 cryotherapy sessions in five years, the average being three. Seven patients had one cryotherapy session, but one patient had seven.
The pain control period was said to have come to an end when the patient reported a recurrence of paroxysmal trigeminal neuralgia which necessitated the consistent use of carbamazepine of $200 \mathrm{mg}$ tds or an equivalent dose of phenytoin for 2 weeks.

Eighty five per cent of patients gained immediate relief of their symptoms, and others required repeat cryotherapy or drug therapy. Long term results when assessed as the total pain control period were not as successful. Of the patients $56.6 \%$ had a pain control period of under one year, $25.3 \%$ for $1-2$ years and $4.8 \%$ for $5-6$ years (fig). However, this short period was often related to migration of the pain to other branches within the same division. This is borne out when one looks at the pain control period for individual nerves which is much longer than the total pain control period (table). I have assessed these for the infra orbital, the mental and the long buccal nerves. Too few freezes of the greater palatine, the posterior superior dental and lingual nerves were done to assess them statistically. In summary, $41 \%$ of patients had a pain control period of over a year, with $14.5 \%$ of patients having a pain control period of over 2 years. However, when looking at nerve pain control periods, it was found that $63 \%$ of nerves had a pain control period of over one year and $34 \%$ of nerves had a pain control period of over 2 years. The only complication was one infection post operatively, which cleared up after a course of antibiotics. All patients regained normal sensation of the face within 2 to 3 months.

Those patients who had repeat cryotherapy had equally good results on the second or any further subsequent times.

\section{Discussion}

No one surgical treatment is a $100 \%$ successful and even if the recurrence rate is low then the morbidity tends to be high.

Treatment by posterior fossa surgery involves either section (partial or total) of the trigeminal sensory root or microvascular decompression as described by Jannetta. ${ }^{13}$ Piatt and Wilkins ${ }^{14}$ feel both procedures are effective and excellent or good results were obtained in $77 \%(105)$ patients. Kolluri and

Table Pain control period (PCP) for individual nerves

\begin{tabular}{|c|c|c|c|c|c|c|}
\hline \multirow[b]{2}{*}{ Time in years } & \multicolumn{2}{|c|}{39 Infraorbital nerves } & \multicolumn{2}{|c|}{30 Mental nerves } & \multicolumn{2}{|c|}{23 Buccal nerves } \\
\hline & $P C P$ & Pain free & $P C P$ & Pain free & $P C P$ & Pain free \\
\hline $\begin{array}{l}0-1 \\
1-2 \\
2-3 \\
3-4 \\
4-5 \\
5-6\end{array}$ & $\begin{array}{l}28 \%(11) \\
31 \%(12) \\
8 \%(3) \\
0 \\
3 \%(1) \\
0\end{array}$ & $\begin{array}{c}5 \%(2) \\
3 \%(1) \\
8 \%(3) \\
3 \%(1) \\
0 \\
13 \%(5)\end{array}$ & $\begin{array}{c}37 \%(11) \\
23 \%(7) \\
7 \%(2) \\
20 \%(6) \\
0 \\
0\end{array}$ & $\begin{array}{l}3 \%(1) \\
3 \%(1) \\
0 \\
0 \\
3 \%(1) \\
3 \%(1)\end{array}$ & $\begin{array}{r}35 \%(8) \\
26 \%(6) \\
17 \%(4) \\
4 \%(1) \\
4 \%(1)\end{array}$ & $\begin{array}{l}4 \%(1) \\
0 \\
0 \\
0 \\
9 \%(2)\end{array}$ \\
\hline
\end{tabular}


Heros $^{15}$ compared several larger series of microvascular decompression and found an average recurrence rate of $22.5 \%$ in a total of 984 patients. Patients are left with no sensory disturbance but post operative complications included a $0.8 \%(8)$ mortality rate. ${ }^{15}$ Therefore, only medically fit patients should be submitted to these procedures. Hence percutaneous approaches to the Gasserian ganglion have become increasingly popular. Radiofrequency thermocoagulation of the Gasserian ganglion as first described by Sweet and Wepsic ${ }^{16}$ gave encouraging results. Spincemaille et $a^{17}$ reported an $85 \%$ success rate in 45 patients and Mittal and Thomas ${ }^{18}$ reported $88 \%$ of 280 procedures pain free at one year. Unfortunately, the lesions are destructive and alter facial sensation. Glycerol chemoneurolysis ${ }^{19}$ appears to produce less numbness and dysaesthesia with $90 \%$ excellent or good results. ${ }^{20}$ However, many patients are medically unfit or unwilling to undergo major surgery with its consequent mortality and morbidity and for this group peripheral techniques are the alternative. Results for all these methods are fairly similar. Alcohol injections have been reported to give pain relief for 11-16 months, ${ }^{3}$ 6-14.3 months ${ }^{4}$ but are not always successful, may result in facial palsies and are painful to perform. Peripheral neurectomies give slightly better results; 33.2 months pain relief $^{2}$ or 26.5 months ${ }^{21}$ but the patient is left with a degree of facial numbness. Peripheral radiofrequency lesions of peripheral nerves ${ }^{5}$ have a recurrence rate of $68 \%$ at one year with an average effectiveness of 9.2 months but the lesions result in less sensory loss than those done at the level of the ganglion.

Cryotherapy with its average recurrence rate of $37 \%$ at one year compares favourably with these other techniques. In common with most of the other peripheral treatments cryotherapy is carried out under local anaesthesia and on an out-patient basis and so no patient needs to be excluded on medical grounds. Its major advantage lies in the fact that sensation returns to the area within 3 months. Nerve damage is, therefore, totally reversible as borne out not only experimentally, 2223 but also clinically. ${ }^{9-1124}$ Return of sensation, no neuroma formation, neuritis or anaesthesia dolorosa, greatly improve the quality of life for these patients. Patients are willing and do undergo repeated cryotherapy with equally good results in order to avoid major surgery.

Cryotherapy has a role to play in the early management of trigeminal neuralgia, although it must be remembered that we are still a long way from achieving the perfect treatment which would result in pain relief with normal sensation and with no necessity for long term drug therapy or major surgery.

I am grateful to Dr FF Nally for his help in the preparation of this paper and for permission to report on his patients and to Miss $\mathrm{J}$ Hammett for her secretarial assistance.

\section{References}

1 Taylor JC, Brauer S, Espir MLE. Long-term treatment of trigeminal neuralgia with carbamazepine. Postgrad Med J 1981;57:16-8.

2 Grantham EG, Segerberg LH. An evaluation of palliative surgical procedures in trigeminal neuralgia. $J$ Neurosurg 1952;9:390-4.

3 Grant FC. Alcohol injection in the treatment of major trigeminal neuralgia. JAMA 1936;107:771-4.

4 Horrax G, Poppen JL. Trigeminal neuralgia. Experiences with, and treatment employed in 468 patients during the past 10 years. Surg Gynaecol Obstet 1935;61:394-402.

5 Gregg JM, Small EW. Surgical management of trigeminal pain with radiofrequency lesions of peripheral nerves. J Oral Maxillofac Surg 1986;44:122-5.

6 Ratner EJ, Person P, Kleinman DJ, Shklar G, Socransky SS. Jawbone cavities and trigeminal neuralgia and atypical facial neuralgias. Oral Surg 1979;48:3-20.

7 Sokolovic M, Todorovic L, Stajcic Z, Petrovic V. Peripheral streptomycin/Lidocaine injections in the treatment of idiopathic trigeminal neuralgia. J Maxillofac Surg 1986;14:8-9.

8 Lloyd JW, Barnard JDW, Glynn CJ. Cryoanalgesia. A new approach to pain relief. Lancet 1976;ii:932-4.

9 Barnard D, Lloyd J, Evans J. Cryoanalgesia in the management of chronic facial pain. $J$ Maxillofac Surg 1981;9:101-2.

10 Nally FF. A 22-year study of paroxysmal trigeminal neuralgia in 211 patients with a 3-year appraisal of the role of cryotherapy. Oral Surg 1984;58:17-23.

11 Nally FF, Flint SR, Bennett SD, Talhi FS. The role of cryotherapy in the management of paroxysmal trigeminal neuralgia. An analysis of 112 patients. J Irish Coll Phys Surg 1984;13: 184-92.

12 Zakrzewska JM, Nally FF, Flint SR. Cryotherapy in the management of paroxysmal trigeminal neuralgia. J Maxillofac Surg 1986;14:4-7.

13 Jannetta PJ. Microsurgical approach to the trigeminal nerve for tic douloureux. Prog Neurol Surg 1976;7:180-200.

14 Piatt JH, Wilkins RH. Treatment of tic douloureux and hemifacial spasm by posterior fossa exploration: therapeutic implications of the various neurovascular relationships. Neurol Surg 1984;14:462-71.

15 Kolluri S, Heros RC. Microvascular decompression for trigeminal neuralgia. A five year follow-up study. Surg Neurol 1984;22:235-40.

16 Sweet WH, Wepsic JG. Controlled thermocoagulations of trigeminal ganglion and rootlets for differential destruction of pain fibres. Part I: trigeminal neuralgia. J Neurosurg 1974;39:143-56.

17 Spincemaille GHJ, Dingemans W, Lodder J. Percutaneous radiofrequency Gasserian coagulation in the treatment of trigeminal neuralgia. Clin Neurol Neurosurg 1985;87:91-4.

18 Mittal B, Thomas DGT. Controlled thermocoagulation in trigeminal neuralgia. J Neurol Neurosurg Psychiatry 1986; 49:932-6.

19 Hakanson S. Trigeminal neuralgia treated by the injection of glycerol into the trigeminal cistern. Neurosurgery 1981;9:638-46.

20 Lunsford LD, Bennett MH. Percutaneous retrogasserian glycerol rhizotomy for tic douloureux: Part I. Neurosurgery 1984;14: 424-30.

21 Freemont AJ, Millac P. The place of peripheral neurectomy in the management of trigeminal neuralgia. Postgrad Med J 1981;57:75-6.

22 Carter DC, Lee PWP, Gill W, Johnston RJ. The effects of cryotherapy on peripheral nerve function. $J \boldsymbol{R}$ Coll Surg Edin 1972;17:25-31.

23 Whittaker DK. Degeneration and regeneration of nerves following cryotherapy. Br J Exp Pathol 1974;55:595-600.

24 Barnard D. The effects of extreme cold on sensory nerves. Ann $R$ Coll Surg 1980;62:180-7. 